\title{
Buccal Fat Pad Anatomy and its Importance for Safe Clinical Procedures: a Review
}

\author{
Beatriz Carmona Ferreira ${ }^{1}$, Luciane Naomi Oguma Watanabe ${ }^{1}$, Alexandre Rodrigues Freire ${ }^{1}$, Paulo Roberto Botacin ${ }^{2}$, Felippe \\ Bevilacqua Prado ${ }^{1}$, Ana Cláudia Rossi ${ }^{1}$
}

1'Department of Biosciences, Piracicaba Dental School, University of Campinas, Piracicaba, SP, Brazil

${ }^{2}$ Department of Basic Sciences, Araçatuba Dental School, Paulista State University, Araçatuba, SP, Brazil

Disclose and conflicts of interest: none to be declared by all authors

\begin{abstract}
Introduction: clinical applications of the buccal fat pad have been reported more frequently in recent years, mainly in Dentistry area. The aim of this study was to review the literature identifying the anatomy of the buccal fat pad, including its development, functional importance and some of its applications in different clinical procedures.

Review: one electronic research database, PubMed, was investigated using the following restricted keywords: "buccal fat pad", "anatomy" and "clinical procedures". Forty-nine articles were found. The final review included thirty-three of them. Publications identified were considered between February 1989 and December 2020.

Conclusion: this review showed that the buccal fat pad is a complex anatomical structure that has essential functions and can be applied to different clinical approaches. It is indispensable for the professionals who work with this structure to know it in detail so to obtain success on the procedures involving the buccal fat pad
\end{abstract}

Keywords: Buccal fat pad; Anatomy; Clinical procedures; Adipose tissue.

\section{Introduction}

The buccal fat pad (BFP) is a specialized adipose tissue mass which lines the masticatory space, located between the buccinator muscle and the mandibular ramus, and separates the muscles of mastication. A thick fascia with septa encapsulates the buccal fat pad and divide it into many fibroadipose compartments. It is thought to contribute to the soft tissue contours of the face and to improve intermuscular movement ${ }^{1-3}$.

Clinical applications of the BFP have been reported more frequently in recent years, mainly in Dentistry area. It can be explained due to its reliability, low complication rate, plasticity, simple use as a flap and easy availability - as it may be achieved by a horizontal buccal incision prolonging backwards from the second upper molar tooth ${ }^{2,4}$.

The knowledge of the buccal fat pad anatomy is essential to ensure a safe clinical procedure, once it has a rich plexus of blood vessels, lymphatic vessels and myelinated nerves. Its blind dissection can lead to an injury to the buccal branch of facial nerve and the parotid duct ${ }^{5,6}$.

The aim of this study was to review the literature identifying the anatomy of the buccal fat pad, including its development, functional importance and some of its applications in different clinical procedures.

\section{Materials and Methods}

\section{Information sources}

One electronic research database, Pubmed, was investigated using the following restricted keywords: "buccal fat pad", "anatomy" and "clinical procedures".

Database searches were performed in December 2020. Forty-nine articles were found. Publications identified were considered between February 1989 and December 2020.

Some articles were not fully available on data sources and/or not related with the BFP issue. Hence, corresponding authors needed to be contacted in order to achieve these references. The final review included thirty-three of them, of which seventeen were original articles, eleven were case reports and five were review articles.

\section{Eligibility criteria}

Studies were included if they reported the anatomy, functional importance or a clinical application of the buccal fat pad.

Excluded studies were those that did not approached the buccal fat pad, were not published in the English language or were not yet published.

The data were extracted from articles according to the context of the literature review approached: anatomy and development, functional importance and clinical applications.

\section{Literature Review}

\section{Anatomy and development}

The BFP is a specialized subcutaneous adipose tissue mass which is surrounded by a thin capsule of connective tissue. It is also named corpus adiposum 
buccae, or buccal fat pad (of Bichat). BFP fills the space between the temporal and pterygoid muscles, and it also fills the space formed between the masseter and buccinator muscles ${ }^{5,6-10}$. Therefore, Stuzin et al. (1990) report that the BFP serves to line the masticatory space, separating the muscles of mastication from each other. The BFP shows a wide range of distribution. Traditional anatomic descriptions ${ }^{5,11}$ state that the BFP has a central body and four extensions or processes: buccal, pterygoid, pterygopalatine and temporal (superficial and deep). The body is centrally positioned, along the posterior maxilla and upper fibers of the buccinator muscle.

According to Arce (2007) $)^{11}$ the average volume of the BFP is approximately $10 \mathrm{~mL}$ with a mean thickness of about $6 \mathrm{~mm}$. The volume of BFP varies throughout life ${ }^{10}$, but usually with no direct relationship to the total body fat present in the individual ${ }^{11}$. The BFP formation begins at 3 months in utero, and the pad increases in size until birth ${ }^{11}$.

At the anterior border of the masseter muscle, BFP emerges as a rounded, biconvex adipose tissue body (Figure 1), named buccal extension or buccal process ${ }^{10}$, and is the most superficial segment of the fat pad and imparts fullness to the cheek. This extension it is highly developed in newborns and children, also known as "suckling pad"5, due to the function of facilitating the act of sucking, especially during the breastfeeding period being significantly important to the prominence of the cheek of the newborn infant.

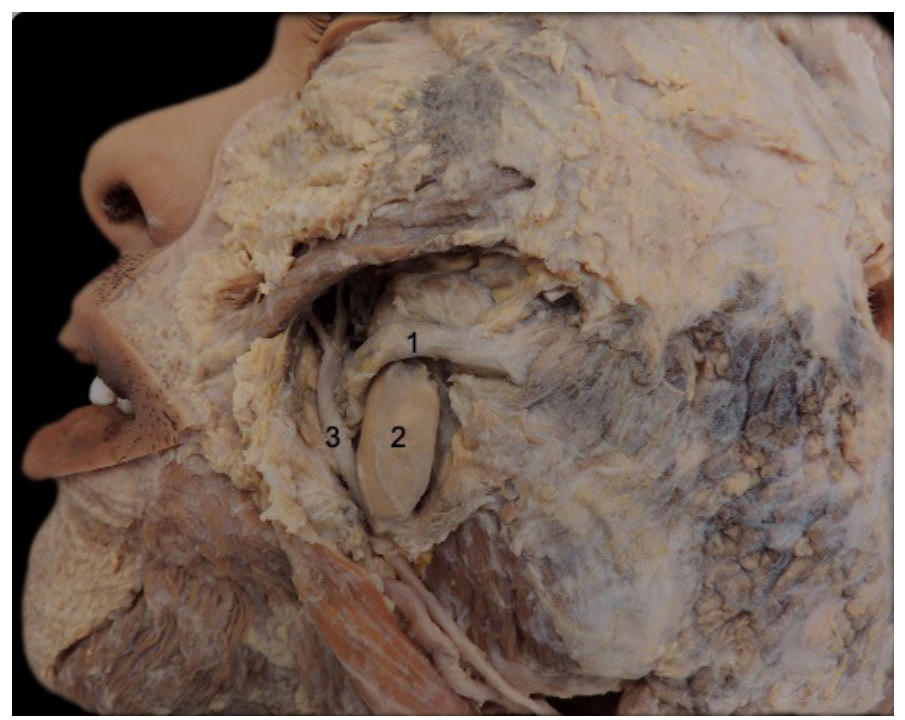

Figure 1. Lateral view of the face. Dissection to visualize the buccal extension of BFP. 1- Parotid duct; 2- Buccal extension of the BFP; 3- Facial vein.

The buccal extension lies superficially within the cheek, and the pterygoid and temporal extensions are more deeply situated ${ }^{5}$. For children, the buccal extension often extends backward and lies on the surface of the masseter ${ }^{12}$.

The buccal extension enters the cheek inferiorly and behind to the parotid duct and extends along the anterior border of the masseter as it descends into the mandibular retromolar region. It overlies the main portion of the buccinator muscle as it crosses the cheek. Its anterior limit is marked by the facial artery and vein, which are in the same plane as the buccal fat pad (Figure 1). The parotid duct lies superficial and superior to the fat pad and then penetrates the fat pad and buccinator muscle to enter the oral cavity opposite the maxillary second molar. The buccal extension is largely responsible for the contour of the cheek $^{5,10}$. The parotid duct and zygomatic and buccal branches (facial nerve branches) are intimately associated with the buccal extension ${ }^{5}$ and, thus, are vulnerable during manipulation.

The superficial temporal extension of the BFP extends upwards towards the temporal fossa, between the anterior border of the temporal muscle and the temporal surface of the zygomatic bone and extends posteriorly, in the form of an adipose mass, between the muscle temporal and temporal fascia. At the level of the deep tendon of the temporal muscle, another extension of the BFP, deep temporal extension, goes backwards towards the pterygomandibular space. This space is limited, laterally, by the medial aspect of the mandibular ramus; medially, through the medial pterygoid muscle; and superiorly by the lateral pterygoid muscle. Deep temporal extension involves the lingual nerve, the inferior alveolar nerve and the inferior alveolar blood vessels, going posteriorly to the anterior face of the deep part of the parotid gland.

While both reside within the temporal region, it is the deep temporal fat pad that is continuous with the buccal fat. The superficial temporal fat pad differs in appearance, has a separate vascular supply, and is anatomically distinct from the buccal fat. The deep temporal extension of the buccal fat passes beneath the zygomatic arch to lie directly on the temporalis and its tendon, separating this muscle from the zygomatic arch. Above the arch, it also passes medially behind the lateral orbital wall and body of zygoma to rest along the greater wing of the sphenoid ${ }^{5}$.

The pterygoid extension is in the pterygoid space in a superior direction, between the two pterygoid muscles and surrounds the lingual and inferior alveolar neurovascular bundles. The pterygopalatine extension extends through the pterygomaxillary fissure and into the pterygopalatine fossa where it encapsulates the pterygopalatine vessels ${ }^{11}$.

\section{Functional importance}

By knowing the BFP anatomy and development, it is possible to realize that it is an essential oral cavity structure and is of notable clinical relevance ${ }^{13}$. It is in the space between the muscles of mastication and, as its function, fills in deep tissue spaces and separates the muscles of mastication from each other, from the zygomatic arch, and from the mandibular ramus. Therewith, it plays a vital role in masticatory function by improving these movements so that the BFP acts 
as cushion while masticatory and mimetic muscles contract, and the gliding surfaces of these muscles do not contact during chewing $5,9,11,14,15$.

Zhang et al. (2002) ${ }^{12}$ affirmed that the functions of the buccal fat pad fill the deep facial spaces such as the masticatory space, infratemporal space, pterygopalatine fossa, anteparotid space, submandibular gland fossa, and the spaces among the mimetic muscles. When the masticatory and mimetic muscles contract, these lobes function as gliding pads.

The volume of the BFP may change throughout a person's life ${ }^{10,12}$. The BFP importance in feeding is also extended to newborns and infants. It is known that the ligaments of the pad give contraction to the negative pressure of suckling and amplify the negative pressure needed for adequate feeding ${ }^{5,11,15}$. It is believed that the lactation effectiveness of the buccinator muscle is raised by the fat pad, and it may inhibit collapse of the cheek during suckling?.

Zhang et al. (2002) $)^{12}$ also reported that the BFP is responsible for protecting the deep facial neurovascular bundles from injury caused by the extrusion of muscle contraction or the outer force impulsion, part of the anterior lobe and the extensions of the posterior lobe pack them and function as a cushion. The BFP provide the protection and cushioning to the deeper vascular and neural bundles of the face against injuries ${ }^{11}$, ${ }^{14}$. Moreover, the BFP has an aesthetic function by supplementing the 'fullness' of the cheeks, and it was reported as being poorly correlated with the general adiposity of the body. It was seen that even slim cadavers with few subcutaneous fat had buccal pads of regular volume and weight $t^{5,14}$.

\section{Clinical applications}

As it could be seen, the BFP is a complex anatomic structure, and it has several clinical applications. It is of interest surgically and recently it has been highlighted mostly due to its clinical implications in both aesthetic and reconstructive surgery ${ }^{7,14,16}$.

The literature review made it possible to collect them all, which will be described below. The table 1 summarized the references and clinical applications of the BFP.

Table 1. References and clinical applications of the BFP found in the literature review.

\begin{tabular}{|c|c|c|}
\hline Reference & BFP use & Clinical application \\
\hline Dubin et al. $(1989)^{37}$ & flap with or without a skin graft & to reconstruct certain contour deformities \\
\hline Stuzin et al. $(1990)^{5}$ & removal (buccal fat harvesting) & $\begin{array}{l}\text { to produce a change in facial contour, reducing cheek } \\
\text { fullness, highlighting the malar eminences and giving a } \\
\text { more sculptured look to the face }\end{array}$ \\
\hline Tostevin and Ellis (1995) ${ }^{7}$ & pedicled graft & $\begin{array}{l}\text { used as a pedicle graft with and without split skin cover, } \\
\text { as a support for a bone graft and as a free fat graft }\end{array}$ \\
\hline Tostevin and Ellis (1995) ${ }^{7}$ & free or pedicled graft & to close maxillary defects after excision of tumors \\
\hline Matarasso $(1997)^{35}$ & removal of fat tissue & to solve congenital buccal lipodystrophy \\
\hline Dean et al. (2001) $)^{17}$ & flap & $\begin{array}{l}\text { to reconstruct small to medium oral defects after tumor } \\
\text { resection }\end{array}$ \\
\hline Zhang et al. (2002) ${ }^{12}$ & random or pedicled buccal fat pad flap & to correct a buccal skin protrusion or hollow \\
\hline Chao et al. $(2002)^{25}$ & graft & $\begin{array}{l}\text { to cover the area of excision of buccal fibrotic tissues } \\
\text { (treatment of the oral submucous fibrosis precancerous } \\
\text { lesion) }\end{array}$ \\
\hline Fan et al. $(2002)^{13}$ & graft & for reconstruction of defects in the oral cavity \\
\hline Alkan et al. (2003) $)^{16}$ & graft & for reconstruction of small to medium-sized oral defects \\
\hline Arce $(2007)^{11}$ & flap & $\begin{array}{l}\text { to reconstruct medium-size maxillary defects like } \\
\text { iatrogenic oro-antral communication in maxillary molar } \\
\text { extractions }\end{array}$ \\
\hline Arce $(2007)^{11}$ & $\begin{array}{l}\text { buccal fat pad flap with additional local } \\
\text { flap or regional pedicle flap }\end{array}$ & to reconstruct large surgical defects \\
\hline Hassani et al. (2009) ${ }^{18}$ & graft & $\begin{array}{l}\text { in sinus lift technique to allow rehabilitation with a fixed } \\
\text { implant-supported prosthesis }\end{array}$ \\
\hline Hassani et al. (2009) ${ }^{18}$ & pedicled flap & used as coverage for oral reconstruction \\
\hline de Wijn et al. (2009)14 & removal of pieces of fat tissue & intraoral resection and removal of lipoma \\
\hline Farré-Guasch et al. $(2010)^{31}$ & source of adipose stem cells & $\begin{array}{l}\text { to obtain chondrogenic, adipogenic, and osteogenic } \\
\text { lineage of cells (tissue engineering) to repair bone and } \\
\text { cartilage defects }\end{array}$ \\
\hline
\end{tabular}




\begin{tabular}{|c|c|c|}
\hline Yousuf et al. $(2010)^{8}$ & flap & $\begin{array}{l}\text { to cover small and medium defects or lesions in oral } \\
\text { reconstruction like congenital palatal defects and } \\
\text { numerous neoplastic lesions }\end{array}$ \\
\hline Khojasteh et al. (2011) $)^{24}$ & pedicled graft & $\begin{array}{l}\text { used in association with Le Fort I osteotomy and sinus } \\
\text { augmentation to gain alveolar bone volume for proper } \\
\text { implant placement }\end{array}$ \\
\hline Chaudhary et al. (2014) & pedicled graft & $\begin{array}{l}\text { to reconstruct small to medium-sized intraoral defects in } \\
\text { the maxilla }\end{array}$ \\
\hline Khiabani et al. (2014)9 & flap & $\begin{array}{l}\text { to fill small and medium-sized soft tissue and bony } \\
\text { defects }\end{array}$ \\
\hline Khiabani et al. (2014) ${ }^{9}$ & pedicle flaps & $\begin{array}{l}\text { to augment the malar area in combination with other } \\
\text { procedures }\end{array}$ \\
\hline Khiabani et al. (2014)9 & buccal fat pad extraction & to lessen buccal fullness principally in obese patients \\
\hline Kishimoto et al. $(2014)^{26}$ & dedifferentiated fat cells source & $\begin{array}{l}\text { for bone tissue engineering, to provide a reliable volume } \\
\text { of tissue to repair bone and periodontal defects }\end{array}$ \\
\hline Weinstock et al. $(2014)^{22}$ & flap & $\begin{array}{l}\text { to obtain soft tissue closure for an oral antral } \\
\text { communication in association with layers of bone and } \\
\text { oral buccal mucosa tissues }\end{array}$ \\
\hline Hernández-Alfaro et al. (2015) ${ }^{23}$ & pedicled flap & $\begin{array}{l}\text { to achieve malar augmentation considering an } \\
\text { orthognathic surgery context }\end{array}$ \\
\hline Jung et al. (2015) & $\begin{array}{l}\text { buccinator myomucosal flap with a } \\
\text { buccal fat pad flap }\end{array}$ & to reconstruct after resection of oropharyngeal cancer \\
\hline Fang et al. $(2017)^{32}$ & source of stem cells & to get clinical bone regeneration \\
\hline Takahashi et al. (2017)33 & $\begin{array}{l}\text { source of differentiated cells derivated } \\
\text { from stem cells of the buccal fat pad }\end{array}$ & $\begin{array}{l}\text { to obtain neurons derivated from human adipose stem } \\
\text { cells of the buccal fat pad to cell replacement therapy of } \\
\text { Parkinson's disease }\end{array}$ \\
\hline Bennet et al. $(2017)^{20}$ & pedicled flap & $\begin{array}{l}\text { to minimize disfiguring and strengthen tenuous closures } \\
\text { in cleft palate repairs }\end{array}$ \\
\hline Bennet et al. $(2017)^{20}$ & flap & palatal fistula repair \\
\hline Baldin et al. $(2018)^{38}$ & $\begin{array}{l}\text { buccal fat pad intraoral surgical } \\
\text { resection }\end{array}$ & $\begin{array}{l}\text { used as therapy for vascular malformations that cover } \\
\text { the buccal fat pad }\end{array}$ \\
\hline Khojasteh et al. (2019) ${ }^{34}$ & source of adipose tissue stem cells & $\begin{array}{l}\text { used in combination with natural bovine bone mineral in } \\
\text { the therapy of large alveolar bone defects to regenerate } \\
\text { bone tissue for dental implant placement }\end{array}$ \\
\hline Katre et al. (2019)10 & flap & $\begin{array}{l}\text { to reconstruct small to medium }(<5 \mathrm{~cm}) \text { acquired or } \\
\text { congenital soft tissue and bony defects in the oral cavity }\end{array}$ \\
\hline Katre et al. (2019) ${ }^{10}$ & flap & $\begin{array}{l}\text { to close big defects when associated with other loco- } \\
\text { regional or distant flap }\end{array}$ \\
\hline Vieira et al. (2019) ${ }^{30}$ & flap & $\begin{array}{l}\text { to close and reconstruct congenital or acquired tissue } \\
\text { defects in the oral cavity }\end{array}$ \\
\hline Vieira et al. (2019) ${ }^{30}$ & buccal fat pad reduction & $\begin{array}{l}\text { to minimize the prominence of the cheek through } \\
\text { facial recontouring in esthetic surgery }\end{array}$ \\
\hline Berenguer et al. $(2020)^{36}$ & buccal fat pad intraoral surgical excision & $\begin{array}{l}\text { surgical treatment of pediatric tumors of the buccal fat } \\
\text { pad }\end{array}$ \\
\hline Echlin et al. $(2020)^{21}$ & flap & $\begin{array}{l}\text { for coverage of fistulae in the soft palate to the posterior } \\
\text { third of the hard palate }\end{array}$ \\
\hline Tsai et al. $(2020)^{29}$ & buccal fat pad reposition & to improve facial aesthetic \\
\hline Surek et al. $(2020)^{28}$ & buccal fat pad excision & to improve lower facial contour \\
\hline
\end{tabular}




\section{BFP as a graft}

The most common clinical application that could be found in the literature is the use of the BFP as a graft. Fan et al. (2002) ${ }^{13}$ and Chaudhary et al. (2014) $)^{15}$ consider the BFP an absolute donor for reconstruction of defects in the oral cavity. It is an easy flap to use, effectively mobilized and has a great blood supply by an abundant plexus of blood vessels. Additionally, it demonstrates potent capacity to resist infections and can be associated with other types of flaps. It's body and buccal extension can be easily accessed through the mouth, by means of an intraoral approach. The BFP flat morbidity and the failure rate are very low, its surgery technique is uncomplicated, well-tolerated and have little complications ${ }^{5,13,15-19}$.

It was reported the use of the BFP as a free fat graft, as a pedicled graft, as a random graft or as a support for a bone graft ${ }^{5,7,12}$. Many indications can be cited regarding the use of the BFP as a graft. The number of cases of its use is increasing, which evinces an inclination in actual reconstructive surgery ${ }^{18}$.

It is possible to find many reports using the BFP graft to close maxillary defects after excision of tumors ${ }^{7,10,15}$, 17,19 , to cover a numberless of oral defects and lesions including congenital palatal defects and numerous

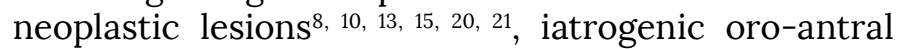
communication $^{10,11,22}$, malar augmentation ${ }^{9,23}$ and sinus augmentation $^{18,24}$.

The BFP flap can be used to fill in small to mediumsized soft tissue and bony defects ${ }^{9}, 10,15,16,17,21$. Arce $(2007)^{11}$ describes the BFP flap as being best suited for medium-size defects up to a maximum $4 \mathrm{~cm}$ in diameter, providing a single stage, worthwhile reconstruction. When using the BFP to cover defects that are larger than $4 \mathrm{~cm}$ in diameter or when the defect is far from the donor site, partial dehiscence, discrepancy in volume and fistula formation can occur secondary to the excessive flap tension necessary to cover them ${ }^{11,18}$. Fan et al. (2002) ${ }^{13}$ believe that an under-tension suture and the entire covering of the surgical defect make the postoperative complications minimized. They also suggest that necrosis or infection of the graft can happen, as with all other grafts.

Bennett et al. (2017) ${ }^{20}$ reported that the BFP is used as a pedicled flap in cleft palate repairs, but little is known about the donor-site morbidity and potential aesthetic consequences of this procedure, because it is a recent technique. Although they defend the use of the BFP, owing to the benefit of no additional cost and bolsters the repair with additional blood supply, they exposed that some surgeons are resistant to this use due to a concern for subsequent facial asymmetry. In their study, there was no statistically significant difference between the donor-site cheek and the nondonor site cheek volumes, which can indicate that BFP harvest does not lead to facial asymmetry when it is used as an adjunct to cleft palate or palatal fistula repair. According to Echlin et al. (2020) ${ }^{21}$, the BFP is a useful tool for coverage of fistulae in the soft palate to the posterior third of the hard palate, and they also report that the technique uses only approximately one-third of the mass of the buccal fat pad, which means that part of the BFP remains within the cheek, and it prevents the patient from unwanted alteration in aesthetics. Chaudhary et al. (2014) ${ }^{15}$ also reported that the use of the BFP in different sizes for the reconstruction of intraoral defects did not generate any distinction in facial contour, and concluded that it is effective, convenient, safe and a rapid procedure of repair for small to medium-sized oral defects.

Chao et al. (2002) ${ }^{25}$ related that the BFP has been used as a graft to cover defects after excision of buccal fibrotic tissues and presented good results in clinical improvement for severely limited mouth opening in cases of oral submucous fibrosis, a precancerous lesion that predominantly affects the people of Indian and Southeast Asia.

Considering the use of the BFP as a graft, there are some aspects that should be highlighted, as its advantages and disadvantages. About the advantages, it is possible to find many authors which described it as a simple flap to use, convenient for the patient, easy of harvesting and well adaptability, and can still be connected with other flaps for reconstruction of large-sized defects, due to its versatile blood supply, $11,15,17,19$. The procedure is of low morbidity and failure rates, can be performed with the patient under local anesthesia and leaves no noticeable scars and cosmetic defect, once the adipose tissue harvesting can be done by an intraoral approach and due to the possibility of performing the technique by a single incision ${ }^{7,8,17,18,26}$. In relation to esthetic advantages, the buccal fat pad mobilization leads to very little facial asymmetry, then, it is often not necessary to excise the contralateral fat ${ }^{8,}$ ${ }^{11}$. Finally, the modification of the fat cells into gingival cells makes it possible to have a better scenario for dental implants ${ }^{18}$.

Towards the disadvantages, the authors point the fact that it can be used only one time ${ }^{15,16}$ and to cover merely small to medium size defects ${ }^{8,17}$. Another feature that is cited is the inability of the buccal fat pad graft to add bulk. Because of its small thickness, it is good to cover defects, but it is not sufficient to provide bulking ${ }^{8,17}$. Besides that, a subtle depression in the cheek can happen in some patients ${ }^{17}$, and the confection of a maxillary full denture may be harmed owing to the lack of vestibular depth and mucosal retention ${ }^{11}$.

Katre et al. (2019) $)^{10}$ emphasized a limitation of this graft, in cases of malignant oral tumors and in cases of tumors going into the masseteric space. They reported that these deep invasive tumors make it necessary to remove the buccal fat pad or part of it, since it is required to get a clear margin.

Some discussions regarding the technique are found in the literature and can assist surgeons working 
in this area. The understanding of the buccal fat pad anatomy and its limits allows a safe execution of reconstructive and aesthetic procedures involving this structure ${ }^{5}$. Arce $(2007)^{11}$ reported that most of the failures involving the use of the BFP was due to partial necrosis. Trismus can happen when the BFP is used in the retromolar trigone area or to reconstruct buccal mucosa defects ${ }^{11}$. Because of this, Dean et al. (2001) recommend starting oral opening exercises from the fifth postoperative day.

Khiabani et al. (2014) $)^{9}$ mentioned that to prevent surgical complications, such as parotid duct injury, accurate dissection must be accomplished. Tostevin and Ellis $(1995)^{7}$ recommend manipulating very precisely the flap, once its vascular supply comes from small arterioles and venules. The surgeon has to take care when handling the flap, perform adequate incision and sutures and maintain the capsule and the vessels of the BFP intact so to achieve success of the technique $^{10,15,19}$. The base of the flap has to be wide, so to maintain the feasibility of it ${ }^{7}$. The flap needs to be free and movable, and if the dissection is not adequate, the blood supply and the volume of the flap can be affected, besides excessive stretching may occur ${ }^{9}$.

Through all these considerations, it is possible to understand that the use of the BFP as a graft has the aim to bring life quality to the patients that underwent tumor or lesions resections, besides improve their oral function and esthetics ${ }^{15}$.

\section{BFP in aesthetic procedures}

Performing of aesthetic procedures has been increasing, and it can involve the BFP, once the size of its buccal process can affect the buccal appearance ${ }^{12}$. Patients are looking for their overall facial esthetics, besides their dental esthetics ${ }^{27}$. There is a tendency going on these techniques due to the search to improve the facial harmony and self-wellness.

These procedures include BFP removal and BFP lifting. Its aim varies, and the literature exposes some of them, as so to repair a buccal skin hollow or protrusion, to exacerbate the malar area and to change the facial contour ${ }^{5,9,12}$.

BFP harvesting has been performed to decrease cheek fullness, alter the facial contour and hence evidence the malar eminence, providing a better appearance harmony ${ }^{5,9}$. Stuzin et al. $(1990)^{5}$ stated that the procedure of BFP removal is indicated to those patients which have unsatisfactorily accentuated cheekbones and absence acking of facial contour, but it is not a substitute for malar augmentation. They also point that it is contraindicated for the patients who present malar hypoplasia or those who miss plenitude in their cheeks.

Combined with other techniques, the BFP removal may lead to a satisfactory versatility when modifying the facial aspect and aesthetic. Surek et al. (2020) ${ }^{28}$ reported that the BFP excision may be a good option to improve the lower facial contour. It can be performed together with orthognathic surgery, face lifting and the repair of masseteric hypertrophy ${ }^{5}$. Tsai et al. (2020) ${ }^{29}$ reported that the excision of the BFP alone does not always reach great aesthetic results.

Moreover, it is possible to use the BFP to augment the malar area, which may be an option for patients who suffered a trauma, mainly when zygomatic fractures occur, and also for those patients who are looking for esthetic improvement, in cases of soft to moderate malar depression ${ }^{9}$. Hernández-Alfaro et al. (2015) ${ }^{23}$ propounded a pedicled BFP technique, which has the aim to stabilize the malar fullness and evidenciation of the zygomatic bone projection as well. This approach has shown a satisfactory stability at a 12-month followup and, in addition, low morbidity and good patient contentment when applied to patients who would be submitted to orthognathic surgical. The malar augmentation using the BFP is not recommended only for the patients who have a low body mass ${ }^{9}$.

Regarding the BFP lifting, Khiabani et al. (2014) ${ }^{9}$ advocated that it should not be done as a separated procedure. It must be combined with orthognathic surgery, malar or paranasal alloplastic augmentation, panfacial fracture surgery, dimple creation surgery or midface lift procedures.

The tendency for cosmetic surgery to become more and more common may be responsible for an increase in lesions and post operatory after-effects ${ }^{30}$. Stuzin et al. (1990) ${ }^{5}$ considered that its complications are minimal, but the surgeon must be careful when dissecting, specially within the masticatory space, and remove solely the portion of the BFP that protrudes into the mouth because there is a risk of lesion to the buccal branch of the facial nerve ${ }^{30}$.

Vieira et al. $(2019)^{30}$ reported a case of a 23 years old, female patient, who has undergone a BFP removal for esthetic reasons and had her parotid gland injured during the procedure. Then she had to be submitted to a new drainage orifice creation. She presented some symptoms, so as excessive swelling in the region, intense pain, fever, trismus and also dysphagia. They emphasize that the surgeon has to ponder the real risks and benefits of the procedure, discuss with the patients its aims on doing it, and perform a correct surgical technique, because it can lead to irreversible complications and lesions in some important structures near the BFP. Tsai et al. (2020) ${ }^{29}$ defend that the plastic surgeons need to keep in mind the supportive function of the deep fat pad, when thinking of excising it.

\section{BFP as a tissue source}

Restoration of lost tissues may be viable due to tissue engineering. It corresponds to an association of the principles of bioengineering, cell transplantation and biomaterial engineering, that has the purpose to seek for a stem cells source for different clinical applications aiming to supply patient's needs with 
minimal morbidity procedures ${ }^{31}$. Cells from the BFP have been considered an ideal source for bone tissue engineering 26,32 .

The BFP is a significant possibility of cell source, being used for tissue engineering, including bone tissue engineering in oral and maxillofacial areas, as so bone repair in alveolar defects, and have been a study object for research on cell replacement therapy of Parkinson's disease $^{24,26,33,34}$. Autologous fat transplantation is applied for adjustment of facial wrinkles, depressed or atrophic areas in the face and scars from acne or trauma ${ }^{27}$.

Stem cells offer an interesting tool for tissue engineering and those harvested from oral tissue are a great source option when looking for bone regeneration $^{31,32}$. Fat tissue has been used for reconstructive surgery ${ }^{27}$. The adipose tissue constitutes a prosperous mesenchymal stem cells source, once it is available in high quantities, is easy to harvest, can be performed with no need of invasive surgery, affords a solid volume of tissue, does not demand the use of general anesthesia and offers very little discomfort to the patients. Furthermore, its size is suchlike in different people and is independent on

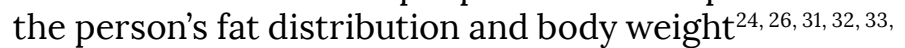
${ }^{34}$. The adipose stem cells are capable to differentiate into vary lineages and express several growth factors, being appropriate for clinical applications ${ }^{31}$.

Dastoor et al. (2007) $)^{27}$ listed some of the advantages of autologous fat. They include the absence of allergies, limitless material source and the low price for the patient and the surgeon as well. According to Kishimoto et al. $(2014)^{26}$, the dedifferentiated cells from the BFP have some advantages on their using. They found out that these cells are more capable to differentiate into osteoblasts than the adipose stem cells and they are simply harvested by an intraoral approach, which makes no esthetic impact.

The results of the study of Farré-Guasch et al. (2010) ${ }^{31}$ showed that BFP cells can differentiate into some diverse lineages, as so the chondrogenic, adipogenic and osteogenic. Because of this, the BFP was defined as a good source for tissue engineering purposes, in addition to its high proportion of cells that can be isolated and expanded in vitro.

A study from Khojasteh et al. (2019) ${ }^{34}$ showed that the use of BFP-derived mesenchymal stem cells maintains proper bone regeneration by performing the guided bone regeneration technique in large alveolar bone defects, and it allows the placement of dental implants. They reported that the use of BFP-derived cells in addition to natural bovine bone mineral may be a satisfactory approach for bone regeneration in these cases. However, a study from Fang et al. (2017) ${ }^{32}$ reported that the dental pulp stem cells presented a higher osteogenic potential when compared with the BFP stem cells and the periodontal ligaments stem cells.
The human BFP seems to be an accessible source of adipose stem cells that may be used for cell therapies in the treatment of Parkinson's disease (PD) ${ }^{33}$. The authors demonstrated that these cells differentiated into neurons and its transplantation improved the symptoms of a rat model of PD, as they survived as neural cells in the brain of those animals. Besides that, they defend that the adipose stem cells derived from the human buccal fat pad might be an applicable source for cell replacement therapy of Parkinson's disease.

\section{BFP excision in some clinical situations}

There are some situations that require the excision of the BFP.

One situation is the herniation of the $\mathrm{BFP}^{8,11,35}$. It is a clinical syndrome characterized by the outward displacement of the most inferior portions of the BFP and can be diagnosed through magnetic resonance imaging. Children are more affected when compared to adults ${ }^{11}$, its etiology occurs because the BFP is more prominent in children and because they tend to put foreign objects into their mouths, making it easier to rupture the buccal mucosa. Besides that, suction may promote herniation along the mucosal defect $t^{11}$.

Even though the excision of the BFP has been reported as a treatment in cases of its herniation, Tsai et al. $(2020)^{29}$ reported that in cases of pseudoherniation the reposition of the BFP may be an option to improve aesthetic outcome.

Other situations that require the excision of the BFP are the cases of lipoma and liposarcoma ${ }^{14,36}$. Resection of the body and the buccal extension is performed in cases of simple lipoma but some cases of diffuse growth, recurrence or suspected liposarcoma demand a more radical approach with resection of the entire $\mathrm{BFP}^{14}$.

Berenguer et al. (2020) ${ }^{36}$ presented a report of two cases of pediatric tumors of the BFP, one lipoma and one hemangioma. In both cases the lesions were excised, through an intraoral approach. According to the authors, this procedure is fast, safe and effective.

Despite being infrequent, the plastic surgeon can find vascular malformations that cover or involve the BFP ${ }^{37,38}$. According to Baldin et al. (2018) ${ }^{37}$, the treatment for this condition is the surgical resection by an intraoral approach. They presented a report of two cases in which the resection of a vascular tumor and a cavernous hemangioma led to the excision of the BFP due to its involvement in the lesions. Performing this technique by an intraoral approach avoids larger scars in the facial region and enables a total resection ${ }^{38}$. Dubin et al. (1989) ${ }^{37}$ also presented a case of an arteriovenous malformation that involved the BFP and led to its complete removal.

\section{Discussion}

The study of the BFP is important to know about the possible applications and risks in clinical practice, 
mainly, in Dentistry and Plastic Surgery procedures. The present literature review identified the anatomy of the BFP, including its development, functional importance and some of its applications in different clinical procedures. Thirty-three articles were evaluated. It was possible to note that it is an essential and complex anatomy structure, with different functions and applicability. The literature review showed that most of articles that report its clinical applications are focused on the use of the BFP as a graft, in aesthetic procedures and as a tissue source.

About the anatomy, the procedures involving the buccal area presented the risk of damaging the facial nerve trunk, although Jung et al. (2015) ${ }^{19}$ related that their cadaveric study showed that direct damages to the trunk seems to be improbable, regarding the location and the depth of the BFP flap, and damages to the digital buccal branches of the facial nerve seems to be more presumable. According to the study of Stuzin et al. (1990) $)^{5}$ the BFP lines what is termed the masticatory space and is intimately associated with the muscles of mastication, facial nerve, and parotid duct. The authors reinforce that to allow safe surgical manipulation, a thorough understanding of these anatomic relationships is required.

The data from this review have shown that it is necessary to be wary when dissecting the BFP flap so to preserve the blood supply, the facial nerve and the parotid duct ${ }^{15}$. Research in this field acts as an important source of information which can make the techniques more valid and reliable ${ }^{18}$.

Looking up at the literature, BFP plays a vital role in masticatory function for adults and for newborns and infants $\mathrm{s}^{5,7,9,11,14,15}$. It participates in protection and cushion of deep vascular and neural bundles of the face $^{11,14}$ and supplements the 'fullness' of the cheeks as well ${ }^{5,14}$.

In this present work, we didn't find in the literature evaluated the mention about the functional importance related with the spread of the odontogenic infections. It's important to emphasize that the BFP participates in the formation of the buccal space, an important fascial space. The buccal tissue space spreads along the lateral surface of the buccinator muscle and the posterior part of it is occupied by the BFP. Thus, the BFP formed the compartment in association with a fascia. The BFP assists to contain odontogenic infections avoiding the propagation of the purulent material by direct continuity.

Some surgeons indicate the BFP removal when patients bite the cheek mucosa (mucosal injury during masticatory function) or simply by aesthetics. As well as other surgical procedures, the BFP removal has its risks, and some complications can occur. However, there are some situations in which it's necessary to remove part of or the entire BFP, including herniation of the $\mathrm{BFP}^{8,35}$, lipoma ${ }^{14,37}$, liposarcoma ${ }^{14}$ and vascular lesions $^{37,38}$, that involve the BFP.

Due to the advances in tissue engineering, the literature reviewed showed several reports ${ }^{24,33,34}$ of its successful use as a restoration of lost tissues. The BFP being used for different clinical applications aiming to supply patient's needs with minimal morbidity procedures.

In conclusion, the review of the BFP anatomy and development, functional importance and clinical applications showed that it is a complex structure with a topography related to many others important noble anatomical structures such as facial nerve and duct of the parotid gland. The BFP has essential functions and can also be applied to many different clinical approaches and situations as a graft, in aesthetic procedures and as a tissue source. It is indispensable for the professionals who work with this structure to know it in detail so they can avoid undesirable situations in their clinical practice and can obtain success on the procedures they perform.

\section{References}

1. Zipfel TE, Street DF, Gibson WS, Wood WE. Traumatic herniation of the buccal fat pad: a report of two cases and a review of the literature. Int J Pediatr Otorhinolaryngol. 1996 Dec 20;38(2):175-9.

2. Amin MA, Bailey BM, Swinson B, Witherow H. Use of the buccal fat pad in the reconstruction and prosthetic rehabilitation of oncological maxillary defects. Br J Oral Maxillofac Surg. 2005 Apr; 43(2):148-54.

3. Cho KH, Lee HS, Katori Y, Rodríguez-Vázquez JF, Murakami G, Abe S. Deep fat of the face revisited. Clin Anat. 2013 Apr;26(3):347-56.

4. Lagier A, Alshawareb F, Layoun W, Lagier JP. Le corps adipeux de la joue dans la reconstruction des pertes de substances postérieures de la cavité buccale [Bichat's buccal fat pad for reconstruction of posterior oral cavity defects]. Rev Stomatol Chir Maxillofac. 2010 Jun;111(3):152-4. French.

5. Stuzin JM, Wagstrom L, Kawamoto HK, Baker TJ, Wolfe SA. The anatomy and clinical applications of the buccal fat pad. Plast Reconstr Surg. 1990 Jan;85(1):29-37.

6. Hwang K, Cho HJ, Battuvshin D, Chung IH, Hwang SH. Interrelated buccal fat pad with facial buccal branches and parotid duct. J Craniofac Surg. 2005 Jul;16(4):658-60.
7. Tostevin PM, Ellis $H$. The buccal pad of fat: a review. Clin Anat. 1995;8(6):403-6.

8. Yousuf S, Tubbs RS, Wartmann CT, Kapos T, Cohen-Gadol AA, Loukas M. A review of the gross anatomy, functions, pathology, and clinical uses of the buccal fat pad. Surg Radiol Anat. 2010 Jun;32(5):427-36.

9. Khiabani K, Keyhan SO, Varedi P, Hemmat S, Razmdideh R, Hoseini

E. Buccal fat pad lifting: an alternative open technique for malar augmentation. J Oral Maxillofac Surg. 2014 Feb;72(2):403.e1-15.

10. Katre MI, Deshmukh SD, Dhanajkar PS, Keche P, Gaikwad A. Buccal Fat Pad a Forgotten Option of Reconstruction in Oral Cancer. Indian J Otolaryngol Head Neck Surg. 2019 Oct;71(Suppl 1):248-252.

11. Arce K. Buccal fat pad in maxillary reconstruction. Atlas Oral Maxillofac Surg Clin North Am. 2007; 15: 23-32.

12. Zhang HM, Yan YP, Qi KM, Wang JQ, Liu ZF. Anatomical structure of the buccal fat pad and its clinical adaptations. Plast Reconstr Surg. 2002 Jun;109(7):2509-18; discussion 2519-20.

13. Fan L, Chen G, Zhao S, Hu J. Clinical application and histological observation of pedicled buccal fat pad grafting. Chin Med J (Engl). 2002 Oct;115(10):1556-9. 
14. de Wijn RS, van der Heijden EP, Kon M. On lipoma of the buccal fat pad: report of two cases and review of the literature. J Plast Reconstr Aesthet Surg. 2009 Jan;62(1):28-35.

15. Chaudhary B, Gong Z, Lin Z, Abbas K, Ling B, Liu H. Reconstruction of intraoral maxillary defect with buccal fat pad. J Craniofac Surg. 2014 Nov;25(6):2174-7.

16. Alkan A, Dolanmaz D, Uzun E, Erdem E. The reconstruction of oral defects with buccal fat pad. Swiss Med Wkly. 2003 Aug 23; 133(3334):465-70.

17. Dean A, Alamillos F, García-López A, Sánchez J, Peñalba M. The buccal fat pad flap in oral reconstruction. Head Neck. 2001 May;23(5):383-8. 18. Hassani A, Khojasteh A, Alikhasi M, Vaziri H. Measurement of volume changes of sinus floor augmentation covered with buccal fat pad: a case series study. Oral Surg Oral Med Oral Pathol Oral Radiol Endod. 2009 Mar;107(3):369-74.

19. Jung BK, Song SY, Kim SH, Kim YS, Lee WJ, Hong JW, Roh TS, Lew DH. Lateral Oropharyngeal Wall Coverage with Buccinator Myomucosal and Buccal Fat Pad Flaps. Arch Plast Surg. 2015 Jul;42(4):453-60.

20. Bennett KG, Thurston TE, Vercler CJ, Kasten SJ, Buchman SR. Harvesting the Buccal Fat Pad Does Not Result in Aesthetic Deformity in Cleft Patients: A Retrospective Analysis. Plast Reconstr Surg. 2017 Aug;140(2):362-368.

21. Echlin K, Whitehouse H, Schwaiger M, Nicholas R, Fallico N, Atherton DD. A Cadaveric Study of the Buccal Fat Pad: Implications for Closure of Palatal Fistulae and Donor-Site Morbidity. Plast Reconstr Surg. 2020 Dec;146(6):1331-1339.

22. Weinstock RJ, Nikoyan L, Dym H. Composite three-layer closure of oral antral communication with 10 months follow-up-a case study. J Oral Maxillofac Surg. 2014 Feb;72(2):266.e1-7.

23. Hernández-Alfaro F, Valls-Ontañón A, Blasco-Palacio JC, GuijarroMartínez R. Malar Augmentation with Pedicled Buccal Fat Pad in Orthognathic Surgery: Three-Dimensional Evaluation. Plast Reconstr Surg. 2015 Nov;136(5):1063-1067.

24. Khojasteh A, Mohajerani H, Momen-Heravi F, Kazemi M, Alikhasi M. Sandwich bone graft covered with buccal fat pad in severely atrophied edentulous maxilla: a clinical report. J Oral Implantol. 2011 Jun;37(3):361-6.

25. Chao CK, Chang LC, Liu SY, Wang JJ. Histologic examination of pedicled buccal fat pad graft in oral submucous fibrosis. J Oral Maxillofac Surg. 2002 Oct;60(10):1131-4.

26. Kishimoto N, Momota Y, Hashimoto Y, Tatsumi S, Ando K, Omasa $\mathrm{T}$, Kotani J. The osteoblastic differentiation ability of human dedifferentiated fat cells is higher than that of adipose stem cells from the buccal fat pad. Clin Oral Investig. 2014 Nov;18(8):1893-901.

27. Dastoor SF, Misch CE, Wang HL. Dermal fillers for facial soft tissue augmentation. J Oral Implantol. 2007;33(4):191-204.

28. Surek CC, Kochuba AL, Said SA, Cho KH, Swanson M, Duraes E, McBride J, Drake RL, Zins JE. External Approach to Buccal Fat Excision in Facelift: Anatomy and Technique. Aesthet Surg J. 2020 Jan 22:sjaa015. 29. Tsai $Y T$, Zhang $Y$, Wu Y, Yang HH, Chen L, Huang PP, Wang CH. The Surgical Anatomy and the Deep Plane Thread Lift of the Buccal Fat Pad. Plast Reconstr Surg Glob Open. 2020 Jun 23;8(6):e2839.

30. Vieira GM, Jorge FD, Franco EJ, Dias LDC, Guimarães MDCM, Oliveira LA. Lesions of the Parotid Gland and Buccal Artery After Buccal Fat Pad Reduction. J Craniofac Surg. 2019 May/Jun;30(3):790-792.

31. Farré-Guasch E, Martí-Pagè C, Hernádez-Alfaro F, Klein-Nulend J, Casals N. Buccal fat pad, an oral access source of human adipose stem cells with potential for osteochondral tissue engineering: an in vitro study. Tissue Eng Part C Methods. 2010 Oct;16(5):1083-94.

32. Fang TJ, Wang DH, Wang CY, Poongodi R, Liou NH, Liu JC, Hsu ML, Hon PD, Yang SF, Liu ML. Correction to: Osteogenic prospective of deriving human dental stem cells in collagen matrix boost. J Mater Sci Mater Med. 2018 Jun 26;29(7):100. doi: 10.1007/s10856-018-6090-0. Erratum for: J Mater Sci Mater Med. 2017 Nov 15;28(12 ):192.

33. Takahashi H, Ishikawa H, Tanaka A. Regenerative medicine for Parkinson's disease using differentiated nerve cells derived from human buccal fat pad stem cells. Hum Cell. 2017 Apr;30(2):60-71.

34. Khojasteh A, Hosseinpour S, Rad MR, Alikhasi M. Buccal Fat PadDerived Stem Cells in Three-Dimensional Rehabilitation of Large Alveolar Defects: A Report of Two Cases. J Oral Implantol. 2019 Feb;45(1):45-54.

35. Matarasso A. Pseudoherniation of the buccal fat pad: a new clinical syndrome. Plast Reconstr Surg. 1997 Sep;100(3):723-30; discussion 7316.

36. Berenguer B, Lorca-García C, Lancharro A, DeTomás E. Pediatric tumors of the buccal fat pad: lipoma and hemangioma. Acta Chir Belg. 2020 Oct;120(5):341-343.

37. Dubin B, Jackson IT, Halim A, Triplett WW, Ferreira M. Anatomy of the buccal fat pad and its clinical significance. Plast Reconstr Surg. 1989 Feb;83(2):257-64.

38. Baldin AV, Telich Tarriba JE, Velázquez Zabaleta E, Apellaniz Campo A, Martinez Wagner R, Cardenas-Mejía A. Surgical Resection of Vascular Lesions Involving the Buccal Fat Pad. J Craniofac Surg. 2018 Jul;29(5):e459-e461.

\section{Mini Curriculum and Author's Contribution}

1. Beatriz Carmona Ferreira - DDS, MSc student. Contribution: effective scientific and intellectual participation of the study, responsible for literature review on database, data organization, data interpretation, preparation and draft of the manuscript, critical review and final approval. ORCID: 0000-0001-6845-7881

2. Luciane Naomi Oguma Watanabe - DDS, MSc student. Contribution: responsible for literature review on database, data organization, preparation and draft of the manuscript, critical review and final approval. ORCID: 0000-0001-5208-0311

3. Alexandre Rodrigues Freire - DDS, MSc, PhD. Contribution: effective scientific and intellectual participation of the study, data interpretation, preparation and draft of the manuscript, critical review and final approval. ORCID: 0000-0002-0175-0896

4. Paulo Roberto Botacin - DDS, MSc, PhD. Contribution: effective scientific and intellectual participation of the study, data interpretation, preparation and draft of the manuscript, critical review and final approval. ORCID: 0000-0003-2787-6160

5. Felippe Bevilacqua Prado - DDS, MSc, PhD. Contribution: effective scientific and intellectual participation of the study, data interpretation, preparation and draft of the manuscript, critical review and final approval. ORCID: 0000-0001-5636-6915 